\title{
Metered Dose Inhaler Technique: A Priority Catch for Physicians
}

Muhammad Ahmed ${ }^{1}$, Muqadas Munir ${ }^{1}$, Ali Sufyan ${ }^{1}$, Jahanzeb Ayyaz ${ }^{1}$, Imran Arshad Sr. ${ }^{2}$, Mujtaba Bukhari $^{1}$, Muhammad Umar ${ }^{3}$, Muhammad Khurram ${ }^{4}$, Ahsan Tariq ${ }^{1}$, Muhammad Hamza ${ }^{5}$

1. Department of Medicine, Rawalpindi Medical University, Rawalpindi, PAK 2. Department of Medicine, Benazir Bhutto Hospital, Rawalpindi, PAK 3. Gastroenterology, Rawalpindi Medical University, Rawalpindi, PAK 4. Department of Medicine, Holy Family Hospital/Rawalpindi Medical University, Rawalpindi, PAK 5. Department of General Surgery, Benazir Bhutto Hospital, Rawalpindi, PAK

Corresponding author: Muhammad Ahmed,mu.ahmed147@gmail.com

\begin{abstract}
Background: Asthma is a non-curable but preventable disease that can be controlled by a proper approach. Inhalational route is considered to be one of the fastest, non-invasive course for the management of asthma. Despite its importance, compliance towards proper inhalational technique remains quite low. Thus, United Kingdom guidelines and Global Strategy for Asthma Management and Prevention (GINA) recommend regular assessment of inhaler techniques in all asthma patients.
\end{abstract}

Objective: To evaluate the inhalational technique of asthma patients visiting out-patient departments of public sector tertiary care hospitals of Rawalpindi and correlate with various demographic factors.

Methods: A cross-sectional study was conducted on a total of 209 respondents visiting the outpatient department of public sector hospitals in Rawalpindi. Asthmatic patients were included via a non-probability consecutive sampling technique and were assessed for inhaler techniques via a structured checklist. Statistical data were analyzed using IBM Statistical Package for Social Sciences (SPSS ${ }^{\circledR}$ ), version 25.0 (IBM Corp., Armonk, NY, USA).

Results: Two hundred and nine asthma patients were included. Only $10 \%$ of patients demonstrated the correct inhaler technique. Continuing inhaling till lungs are full, holding breath for five to 10 seconds, and breathing out slowly after using the inhaler were most poorly followed.

Conclusion: Most asthma patients are using poor inhalation technique, risking sub-optimal drug delivery and inadequate effects. Hence, it is the need of the hour to focus on patient training and education.

Received 08/18/2020

Review began 09/08/2020

Review ended 10/04/2020

Published 10/08/2020

(c) Copyright 2020

Ahmed et al. This is an open access article distributed under the terms of the Creative Commons Attribution License CC-BY 4.0., which permits unrestricted use, distribution, and reproduction in any medium, provided the original author and source are credited.
Categories: Internal Medicine, Allergy/Immunology, Pulmonology

Keywords: asthma, inhalational technique, metered dose inhalers, inhaler administration checklist, pakistan, rawalpindi

\section{Introduction}

Asthma is an inflammation of the airways so its treatment comprises medications given via inhalational route [1]. Inhalational route is considered to be one of the fastest, non-invasive courses for the treatment of asthma [2]. The most common inhalational devices are metered dose inhalers (MDI), dry powdered inhalers (DPI), and nebulizers [3]. Improper inhalational technique is one of the major causes of poor asthmatic control because it leads to inadequate delivery of the drug to the respiratory tract, causing poor control of asthma [4]. Over the past 30 years, incorrect use of inhalational devices and its consequences have been documented [5]. The most commonly known mistakes associated with inhalational techniques include failure to exhale before activation, inadequate breath-holding after inhalation, improper positioning of inhalational device, wrong rotation sequence, and improper execution of forceful and deep inhalation [6].

The United Kingdom guidelines and Global Strategy for Asthma Management and Prevention (GINA) recommend that inhaler techniques should be regularly assessed in all asthma patients [7]. A study in Nigeria found more use of MDIs as compared to other inhalational techniques. According to this study, a patient's education directly influences the inhalational technique [8]. A study conducted in Oman showed good asthmatic control to be dependent upon good inhaler techniques [9]. A Netherlands based study showed that as compared to DPIs, MDIs, Rota haler, and Trubuhaler lead to more inhalational errors [10]. A univariate analysis conducted in the USA showed better adherence to inhalational drugs among DPI users [11]. A study conducted in New Delhi, India showed maximum mistakes while using inhalational devices were committed by self-educated patients followed by those trained by pharmacists and health care professionals. Moreover, it also depicted that MDIs and nebulizers are associated with more errors as compared to DPIs [12]. A study of Civil Hospital Karachi showed more usage of MDIs by asthma patients followed by DPIs [13]. A Pakistan-based study demonstrated an inverse relationship between the education 
The rationale of this study is to evaluate the inhalational techniques of asthma patients visiting outpatient departments of a public sector tertiary care setting in Rawalpindi, Pakistan; to assess common mistakes performed while using inhalational devices, and to discuss insinuation for clinical benefit of asthma patients. Different factors influencing inhalational techniques including patient's age, sex, education level, and training regarding inhaler use will be assessed. This study will help in devising new strategies in treatment plans and patients' education for better control of asthma.

\section{Materials And Methods}

This cross-sectional study was conducted at a public sector tertiary care setting after approval from the Institutional Research Forum. Using the World Health Organization (WHO) sample size calculator with 95\% confidence level, $5 \%$ margin of error, and $16.3 \%$ estimated prevalence the sample size was calculated to be 209 [14].

Patients were included via a non-probability consecutive sampling technique. Patients of age greater than 12 years diagnosed with asthma and using MDIs as inhalers were included in the present study. Patients using inhalers others than MDIs or diagnosed on the same visit were excluded from the study. The procedure was explained individually to the patients and prior verbal consent was taken. Using structured proforma, demographic data including patient gender, age, educational status, and economic status was collected from patients. Data regarding the duration of use and place of first prescription was also taken. The inhaler technique was assessed using a 10-step standard checklist adopted from American guidelines.

Data was entered on Intel Business Machine Statistical Package for Social Sciences (SPSS) version 25 (IBM Corp., Armonk, NY, USA). Descriptive analysis was done on quantitative variables while frequency tables were applied to assess qualitative variables. The patient's inhalational technique was considered correct if eight or more out of ten steps were correct according to the checklist. Pearson's correlation was used to determine the statistical significance of factors affecting inhalational technique.

\section{Results}

Out of a total of $209,56.5 \%(n=118)$ were male and $43.5 \%(n=91)$ were female. Mean age of patients was 37.4 \pm 22.1 years. Patient characteristics are given in Table 1 . 


\section{Cureus}

Variable

N (\%)

Gender

Male

Female

118 (56.5)

91 (43.5)

Age (years)

Mean (SD)

Educational Status

No formal education

Literate

Economic Status

Lower

Middle

Place of first prescription

Tertiary care

Non Tertiary care

Duration of use

24 months or less

More than 24 months
$37.4( \pm 22.1)$

111 (53.1)

98 (46.9)

145 (69.4)

64 (30.6)

145 (69.4)

$64(30.6)$

80 (38.3)

129 (61.7)

\section{TABLE 1: Characteristics of studied patients}

SD: standard deviation

Only $10 \%(n=20)$ used the inhaler with correct technique while $90 \%(n=209)$ had an incorrect technique (Figure 1).

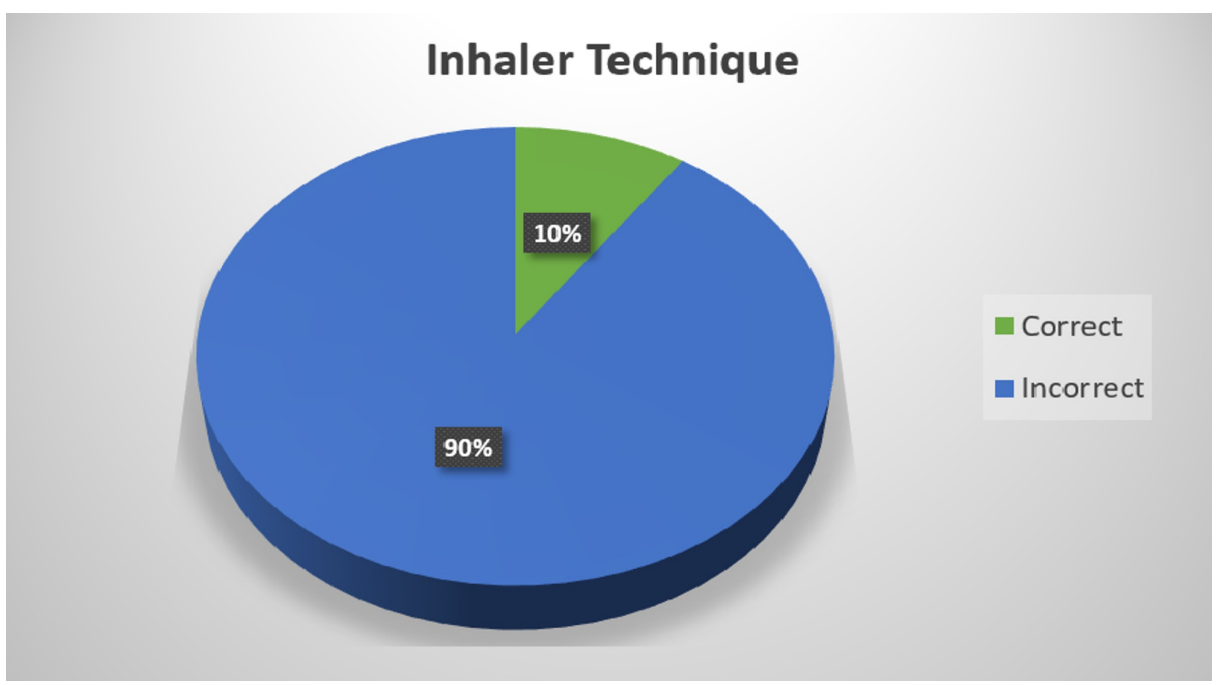

FIGURE 1: Pie chart representing percentage of patients using correct inhaler technique.

Pearson's chi-square was applied to see the association of gender, educational status, economic status, place 
of first prescription and duration of use with inhaler technique. Females were more likely to use the incorrect technique $\left(\mathrm{x}^{2}(1)=0.113 \mathrm{p}=0.737\right)$. Patients with no formal education were also more likely to use an incorrect technique $\left(\mathrm{x}^{2}(1)=0.086 \mathrm{p}=0.769\right)$. Patients with the lower middle class and those who were prescribed inhalers at tertiary care settings were more likely to use the incorrect technique $\left(\mathrm{x}^{2}(1)=0.200\right.$ $\mathrm{p}=0.655, \mathrm{x}^{2}(1)=1.175 \mathrm{p}=0.278$, respectively). Patients using the inhaler for more than 24 months were also more likely to use the incorrect technique $\left(\mathrm{x}^{2}(1)=1.286 \mathrm{p}=0.257\right)$, however, these associations were not significant (Table 2).

\begin{tabular}{|c|c|c|c|c|}
\hline Characteristic & Correct Technique N (\%) & Incorrect Technique N (\%) & Total N (\%) & $x^{2}$ (P value) $^{*}$ \\
\hline Gender & $20(10)$ & $189(90)$ & $209(100)$ & $0.113(0.737)$ \\
\hline Male & $12(10.2)$ & $106(89.8)$ & 118 & \\
\hline Female & $8(8.8)$ & 83 (91.2) & 91 & \\
\hline Educational Status & $20(10)$ & $189(90)$ & 209 (100) & $0.086(0.769)$ \\
\hline No formal education & $10(9)$ & $101(91)$ & 1111 & \\
\hline Literate & $10(10.2)$ & $88(89.8)$ & 98 & \\
\hline Economic Status & $20(10)$ & $189(90)$ & 209 (100) & $0.200(0.655)$ \\
\hline Lower & $13(9)$ & $132(91)$ & 145 & \\
\hline Middle & $7(10.9)$ & $57(89.1)$ & 64 & \\
\hline Place of first prescription & $20(10)$ & $189(90)$ & 209 (100) & $1.175(0.278)$ \\
\hline Tertiary care & $16(11)$ & $129(89)$ & 145 & \\
\hline Non Tertiary care & $4(6.3)$ & $60(93.8)$ & 64 & \\
\hline Duration of use & $20(10)$ & $189(90)$ & $209(100)$ & $1.287(0.257)$ \\
\hline 24 months or less & $10(12.5)$ & 70 (87.5) & 80 & \\
\hline More than 24 months & $10(7.8)$ & $119(92.2)$ & 129 & \\
\hline
\end{tabular}

TABLE 2: Comparison of inhaler technique according to characteristics of patients

Out of 10 steps of inhaler technique according to American guidelines, the most-followed steps were to take the cap off the inhaler, hold the inhaler upright, place the mouthpiece between lips, and trigger the inhaler. The least-followed step was to hold the breath for five to 10 seconds - followed by only $15 \%$ of patients.

\section{Discussion}

This hospital-based observational study of 209 asthma patients showed that the majority of patients are using incorrect inhaler techniques. The study showed that only $10 \%$ of asthma patients using MDIs have correct inhaler techniques and were able to complete all steps as per American guidelines, however, a similar study conducted in asthma patients in Nigeria showed that $22.1 \%$ of patients practice correct inhaler technique [8]. Similarly, van Beereendonk et al. in the Netherlands showed that $11.1 \%$ of asthma patients complete the required steps of correct inhaler technique [15]. Among a total of 10 steps of correct inhaler technique as per American guidelines, our study showed that the least-practiced step is holding the breath while counting to 10 , which is practiced appropriately by only $7.6 \%$ of the total study population; however, an American study showed that about 50\% of asthma patients practice this step while using inhalers [11]. The most common error in the use of MDI in our study was step 8, holding the breath for five to 10 seconds, while the study in Nigeria and other studies identified step 7, continuing to inhale until lungs are full, as the most common mistake made by MDI users $[10,16]$.

Our study showed that illiterate asthma patients are more likely to use incorrect inhaler technique as compared to literate patients. Patients having formal education have comparatively better inhaler technique than those with no education; however, tests of significance didn't show a significant association between educational status and inhaler technique. Our result is similar to a study conducted in Karachi which showed that patients with no education and under matriculate group had incorrect inhaler technique [14]. The result 
is also comparable to the study conducted in Nigeria which showed only a few asthma patients with no formal or with primary education completed the steps of inhaler technique than those with secondary and tertiary education [8]. Therefore, educational status and inhaler technique have an inverse relation to each other.

The present study showed a non-significant association between female gender and incorrect inhaler technique; females were found to be more likely to use an incorrect inhaler technique than males. Similarly, Goodman et al. observed the inhalational technique of males to be better than females [17]. On the contrary, Gray et al. found no significant association between sex and incorrect MDI inhaler technique among asthma patients [18]. Our study concluded that patients belonging to the lower middle class have more incorrect inhaler techniques than upper-middle and higher class, however Pearson's chi-square test did not show a significant association between economic status and correct inhaler technique. This result is comparable to a study conducted in New Delhi, India, which showed that maximum errors in inhaler technique were made by patients belonging to low economic status [12]. Patients prescribed inhalers at tertiary care settings are more likely to use incorrect technique, however, this association was not significant. Our study showed that patients using the inhaler for more than 24 months are more likely to use incorrect technique than those using less than 24 months. This is similar to a study in Saudi Arabia which stated that patients diagnosed with asthma for less than 24 months used inhaler improperly compared to those diagnosed for more than 24 months [19].

The present study is not without limitations; it could not be assessed whether the patients were taught the correct inhalational technique by the health care professionals in the first place. A Brazil-based study has highlighted how a majority of health care professionals were unable to demonstrate adequate technique [20]. Hence, the knowledge of health care professionals and effective communication might be playing a crucial role in determining the adequate inhalational technique. Additionally, the patient's education on compliance, importance of adequate inhalational technique, and poor mini-mental state examination might be some other significant factors $[8,10]$. Aside from studying the determinants of inhaler technique, an insight on its outcomes appears to be equally concerning. Improper inhalation technique and poor compliance have been independently linked with achieving poor asthma controls $[9,21]$.

This study forms the basis to generate future work in this novel area, including assessment of health-care providers knowledge of correct inhaler technique. It will equally form the basis of continued education of the patients who use these inhalers during their routine hospital visits. In order to ensure optimal drug delivery and subsequently achieve asthma control, it is of utmost importance to devise effective patient-directed educational strategies and regular assessments of patient compliance.

\section{Conclusions}

Despite the availability of adequate guidelines and manuals, most of the asthma patients were using poor inhalational techniques. Prolonged usage and prescription from a tertiary care setup were a risk factor for poor inhalational technique. Patients who were illiterate and those who belonged to poor socioeconomic status were found to be at higher risk of using poor inhaler technique. Hence, it is imperative to focus on patient training and education as it is putting patients at risk for not achieving optimal asthma control and thereby losing compliance.

\section{Additional Information \\ Disclosures}

Human subjects: Consent was obtained by all participants in this study. Institutional Research Forum (IRF), Rawalpindi Medical University issued approval Not applicable. Institutional Research Forum (IRF), Rawalpindi Medical University headed by Prof. Dr. M. Khurram reviewed and approved "Metered Dose Inhaler Technique; A Priority Catch For Physicians" and declared it free from ethical discrepancies. ․ Animal subjects: All authors have confirmed that this study did not involve animal subjects or tissue. Conflicts of interest: In compliance with the ICMJE uniform disclosure form, all authors declare the following: Payment/services info: All authors have declared that no financial support was received from any organization for the submitted work. Financial relationships: All authors have declared that they have no financial relationships at present or within the previous three years with any organizations that might have an interest in the submitted work. Other relationships: All authors have declared that there are no other relationships or activities that could appear to have influenced the submitted work.

\section{References}

1. Basheti IA, Qunaibi E, Bosnic-Anticevich SZ, et al.: Use error with diskus and turbuhaler by asthma patients and pharmacists in Jordan and Austalia. Respir Care. 2011, 56:1916-23. 10.4187/respcare.01205

2. Sharma S, Chhabra G, Luhadia SK: Knowledge, attitude, practices of inhalational therapy among nursing staff posted at tertiary care teaching hospital. Int J Res Med Sci. 2017, 5:4285-88. 10.18203/23206012.ijrms20174188

3. Levia-Frenandez F, Levia Fernandez J, Zubeldia-Santoyo F, et al.: Efficacy of two educational interventions about inhalation techniques in patients with chronic obstructive pulmonary disease (COPD). TECRPOC: 
study protocol for a partially randomized controlled trial (preference trial). Trials. 2012, 13:64. 10.1186/1745-6215-13-64

4. Basheti IA, Armour CL, Reddel HK, Bosnic-Anticevich SZ: Long-term maintenance of pharmacists' inhaler technique demonstration skills. Am J Pharm Educ. 2009, 73:32. 10.5688/aj730232

5. Self TH, Arnold LB, Czosnowski LM, Swanson JM, Swanson H: Inadequate skill of healthcare professionals in using asthma inhalation devices. J Asthma. 2007, 44:593-8. 10.1080/02770900701554334

6. Lavorini F, Magnan A, Dubus JC, et al.: Effect of incorrect use of dry powder inhalers on management of patients with asthma and COPD. Resp Med. 2008, 102:593-604. 10.1016/j.rmed.2007.11.003

7. Levy MK, Hardwell A, Mcknight E, Holmes J: Asthma patient's inability to use a pressurized metered-dose inhaler (pMDI) correctly correlates with poor asthma control as defined by the Global Initiative for Asthma (GINA) strategy: a retrospective analysis. Prim Care Respir J. 2013, 22:406-11. 10.4104/pcrj.2013.00084

8. Onyedum CC, Desalu OO, Nwosu NI, Chukwuka CJ, Ukwaja KN, Ezeudo C: Evaluation of inhaler-techniques among asthma patients seen in Nigeria: an observational cross sectional study. Ann Med Health Sci Res. 2014, 4:67-73. 10.4103/2141-9248.126617

9. Baddar S, Jayakrishnan B, Al-Rawas OA: Asthma control: importance of compliance and inhaler technique assessments. J Asthma. 2014, 51:429-34. 10.3109/02770903.2013.871558

10. Hesselink AE, Penninx BW, Wijnhoven HA, Kriegsman DM, van Eijk JT: Determinants of an incorrect inhalation technique in patients with asthma or COPD. Scand J Prim Health Care. 2001, 19:255-60. 10.1080/02813430152706792

11. Roy A, Battle K, Lurslurchachi L, Halm EA, Wisnivesky JP: Inhaler device, administration technique, and adherence to inhaled corticosteroids in patients with asthma. Prim Care Respir J. 2011, 20:148-54. 10.4104/pcrj.2011.00022

12. Arora P, Kumar L, Vohra V, et al.: Evaluating the technique of using inhalation device in COPD and bronchial asthma patients. Resp Med. 2014, 108:992-98. 10.1016/j.rmed.2014.04.021

13. Farooq MZ, Farooq MS, Waqar W, Mustaqeem M, Khan JA, Saadullah S: Assessment of inhalation technique among patients of chronic respiratory disorders in Civil Hospital Karachi: a cross-sectional study. J Pak Med Assoc. 2016, 66:1502-1506.

14. Hashmi A, Soomro JA, Memon A, Soomro TK: Incorrect inhaler technique compromising quality of life of asthmatic patients. J Medicine. 2012, 13:16-21. 10.4103/2141-9248.126617

15. van Beerendonk I, Mesters I, Mudde AN, Tan TD: Assessment of the inhalation technique in outpatients with asthma or chronic obstructive pulmonary disease using a metered-dose inhaler or dry powder device. J Asthma. 1998, 35:273. 10.3109/02770909809068218

16. Melani AS, Bonavia M, Cilenti V, et al.: Inhaler mishandling remains common in real life and is associated with reduced disease control. Respir Med. 2011, 105:930-8. 10.1016/j.rmed.2011.01.005

17. Goodman DE, Israel E, Rosenberg M, Johnston R, Wwiss ST, Drazen JM: The influence of age, diagnosis and gender on proper use if metered-dose inhalers. Am J Respir Crit Care Med. 1994, 150:1256-61. 10.1164/ajrccm.150.5.7952549

18. Gray SL, Williams DM, Pulliam CC, Sirgo MA, Bishop AL, Donohue JF: Characteristics predicting incorrect metered-dose inhaler technique in older subjects. Arch Intern Med. 1996, 156:984-8. 10.1001/archinte.1996.00440090084008

19. Al-Jahdali H, Ahmed A, Al-Harbi A, et al.: Improper inhaler technique is associated with poor asthma control and frequent emergency department visits. Allergy Asthma Clin. 2013, 9:8. 10.1186/1710-1492-9-8

20. Stelmach R, Robles-Ribeiro PG, Ribeiro M, Oliveira JC, Scalabrini A, Cukier A: Incorrect application technique of metered dose inhalers by internal medicine residents: impact of exposure to a practical situation. J Asthma. 2007, 44:765-8. 10.1080/02770900701645694

21. Hamdan AJ, Ahmed A, Abdullah AH, et al.: Improper inhaler technique is associated with poor asthma control and frequent emergency department visits. Allergy Asthma Clin Immunol. 2013, 9:8. 10.1186/17101492-9-8 